\title{
OLHARES \\ Audiovisual, saúde e educação: limitações e possibilidades do aprendizado coletivo com adolescentes no interior do estado do Ceará
}

\begin{abstract}
Técnico de Referência do Centro de Referência de Assistência Social (CRAS), Sede de Umirim-CE diegomendoncaviana@gmail.com

Marcio Sacramento de Oliveira Pesquisador da Escola Politécnica de Saúde Joaquim Venâncio (EPSJV/Fiocruz) marcio.sacramento@fiocruz.br

Maria de Fátima Ebole Santana Pesquisadora convidada da Escola Politécnica de Saúde Joaquim Venâncio (EPSJV/Fiocruz) mfebole@gmail.com
\end{abstract}

\section{RESUMO}

Este trabalho objetivou discutir os diversos e complexos fatores que envolvem o uso de tecnologias audiovisuais no desenvolvimento de habilidades e competências críticas em saúde e em educação entre adolescentes em uma instituição municipal de Assistência Social. Trata-se de uma pesquisa-ação cuja metodologia consistiu na análise qualitativa de caráter interventivo com a realização de três oficinas para levantamento de temas relevantes, com a construção de roteiros e de gravações de vídeos sobre a realidade dos adolescentes participantes. Os resultados obtidos foram o aprendizado de habilidades e competências sobre as políticas públicas do território por meio da produção de vídeos de curta duração, bem como a reflexão sobre o uso do audiovisual como ferramenta de criticidade. Concluiu-se que houve aprendizado do manuseio de tecnologias audiovisuais e discussão de temáticas pertinentes à realidade dos adolescentes, assim como, houve abertura para a utilização do audiovisual na instituição, mesmo em um contexto com pouco acesso a recursos tecnológicos.

Palavras-chave: Saúde; Educação; Audiovisual.

\section{Audiovisual, health and education: limitations and collective learning possibilities with teenagers in the countryside of Ceará state, Brazil}

\section{ABSTRACT}

This work aimed to discuss the diverse and complex factors that involve the use of audiovisual technologies in the development of critical skills and competences in health and 
education among adolescents in a municipal institution of Social Assistance. It is a researchaction whose methodology consisted of a qualitative analysis of an interventional character with the realization of three workshops to survey relevant topics, with the construction of scripts and video recordings about the reality of the participating adolescents. The results obtained were the learning of skills and competences on the public policies of the territory through the production of short videos, as well as the reflection on the use of audiovisual as a critical tool. It was concluded that there was learning in the handling of audiovisual technologies and discussion of themes relevant to the reality of adolescents, as well as, there was an opening for the use of audiovisual in the institution, even in a context with little access to technological resources.

Keywords: Health; Education; Audiovisual.

\section{Introdução}

Este artigo é resultado da análise de elementos da experiência profissional e se constitui como um esforço científico de discussão de temáticas de fronteira nos campos de saúde e educação, tendo a proposta de produção organizada de audiovisual como um vetor de aprendizagem a respeito de diversas temáticas em ambientes em que há práticas de ensino.

Neste sentido, o tema escolhido para análise foi o incentivo à produção de audiovisual por parte de adolescentes que já realizavam esta prática em uma instituição municipal de Assistência Social. Após a realização de um diagnóstico situacional na instituição e, em razão do amadurecimento propiciado pelas atividades desenvolvidas junto aos adolescentes por parte de um dos autores, elaborou-se um projeto de intervenção profissional que foi sendo desenhado como uma atividade contextualizada a ser apresentada para todos e todas que fizeram parte do objeto de estudo. Uma das principais motivações de trabalhar com esta temática se deu em função da percepção de que os adolescentes, predominantemente, utilizam a produção de vídeos amadores como um recurso de construção de identidades e de comunicação nas instituições e na comunidade.

As atividades citadas são típicas de uma instituição de assistência social de um município do interior do estado do Ceará com população estimada em 20 mil habitantes e localizado cerca de $89 \mathrm{~km}$ da capital Fortaleza, sendo componentes da matriz de aprendizado das oficinas de cidadania. As atividades de cidadania fazem parte do Serviço de Convivência e Fortalecimento de Vínculos (SCFV). Este serviço e as atividades a ele concernentes estão vinculadas diretamente ao Centro de Referência de Assistência Social (CRAS) do município em questão, com público médio de 60 pessoas distribuído entre crianças e adolescentes (idades de 07 a 17 anos).

Os participantes do SCFV com foco deste estudo são adolescentes e estudantes de diversas escolas de ensino fundamental e ensino médio do bairro, bem como de bairros vizinhos que fazem parte do território da unidade de Assistência Social analisada. Em relação ao desempenho escolar médio dos estudantes, observa-se que há variações, oscilando entre um grau de escolarização relevante de uma parte deles e baixíssima escolarização de outra parte. Este fator impacta na necessidade de se buscar metodologias, que sejam mais inclusivas possíveis, para que todos os públicos consigam participar das 
atividades.

Os adolescentes que participam das atividades na instituição são de faixas etárias correspondentes entre 12 e 17 anos, todos (as) residentes em bairros periféricos e socialmente vulneráveis da cidade. Um dos objetivos da política pública de Assistência Social é mobilizar, bem como integrar crianças, adolescentes e jovens que estão em condições de vulnerabilidade social nas comunidades em que se situam os CRAS. Pretende-se que este público possa desenvolver atividades esportivas, lúdicas, artísticas sobre os direitos sociais e para fortalecer a convivência em cultura de paz. Neste sentido, no caso específico da instituição em que este estudo ocorreu, os adolescentes frequentam as atividades de cidadania pelo menos duas vezes por semana, no contraturno da escola, para desenvolver diversas atividades dentro deste objetivo citado acima. Os trabalhos foram conduzidos por orientadores sociais e professores de atividades especificas (exemplo: informática, artes plásticas e música), bem como os (as) adolescentes contam com uma equipe técnica de acompanhamento composta por um psicólogo e uma assistente social.

Importante frisar que um dos autores deste estudo é integrante da equipe técnica acima mencionada e teve como desafio construir conhecimento científico a partir da interrelação cotidiana com os adolescentes na instituição. Este contexto possui facilidades e dificuldades de se fazer um tipo de atuação de pesquisa no próprio ambiente de trabalho que serão detalhadas nas seções a seguir.

$\mathrm{Na}$ realização das atividades de promoção de cidadania na instituição, os adolescentes, constantemente, vinham mostrar para a equipe técnica, bem como para os orientadores sociais pequenos vídeos que eles tinham feito de forma simples sobre a sua realidade no bairro. Este fato chamou a atenção para a um interesse em trabalhar com esse tipo de mídia. Estes vídeos produzidos por demanda livre e fora do contexto deste estudo eram postados por pouco tempo nas redes sociais dos adolescentes.

Uma parte dos vídeos amadores gravados pelos adolescentes eram publicados em redes sociais: Facebook e em canais de broadcasting como o Youtube. Por vezes, estes vídeos também são publicados nas mídias sociais oficiais da instituição e se configuraram como um espaço de visibilidade, sentimentos de pertencimento e de coletividade (ARAúJO et al, 2016). Este cenário permitiu supor que o incentivo e a mediação da produção de vídeos com o propósito do uso crítico destas ferramentas para o contexto de aprendizado sobre educação, saúde e cidadania poderia ser uma ferramenta potente. Segundo Vargas et al (2007), a utilização de vídeos é um caminho relevante, dentre outros motivos, por incentivar o desenvolvimento da base do pensamento analítico/crítico necessário para que os alunos se tornem consumidores mais observadores e críticos em relação aos produtos desse tipo de mídia; bem como a promoção da expressão e da comunicação, cujos os alunos envolvidos nesse tipo de atividade tendem a superar a timidez e ampliar seu espaço discursivo.

Outra possibilidade foi a percepção de que a utilização de vídeos seria uma das alternativas para que o processo de aprendizagem ocorresse de forma mais significativa.

No debate entre uso de mídias audiovisuais e juventude, há uma multiplicidade de estudos que abordam o tema. Destacam-se alguns dados apontados pelos estudos de Rosado et al (2015) quanto ao uso de mídia por adolescentes: 


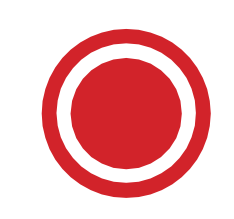

Existe uma forte influência do fator idade para a definição do aprofundamento nos
usos das redes sociais on-line pelos jovens. À medida que vão amadurecendo, mais
amigos são feitos (laços fracos), mais amizades fora do espaço de convivência
presencial são tecidas, diminuindo a comunicação com pais e professores. Eles vão
se tornando mais independentes e passam a acessar as redes via celular e
computador pessoal, entrando aos poucos na lógica do multiacesso e da mobilidade
e publicando conteúdos próprios com maior frequência. Apesar da forte participação
nas redes, os jovens tendem mais a reproduzir e compartilhar conteúdos de terceiros
do que a produzir seus próprios. A produção de vídeos e áudios não é prioritária para
eles, que postam mais conteúdos na forma de mensagens textuais e fotográficas.
(p.22)

Diante deste cenário apresentado pelos autores acima, restava confrontar essa constatação da literatura sobre mídia e juventude no contexto de trabalho em que o estudo se desenvolveu. A percepção do cotidiano permitia supor que havia interesse crescente dos adolescentes em usar o audiovisual como uma estratégia de produção de mídia e também como uma estratégia de discussão de sua identidade e do seu território. A realização da intervenção poderia indicar um maior ou menor interesse dos participantes sobre a produção de audiovisual.

Ao se pesquisar na base de dados de Descritores em Ciências da Saúde (DECs) da Biblioteca Virtual em Saúde (BVS), verificou-se que o termo Audiovisual remete a dois descritores-chave que são: "Gravação Audiovisual" e "Mídia Audiovisual". O descritor de Saúde remete a 456 descritores correlatos em assunto e o descritor Educação remete a 66 descritores correlatos. Em uma busca preliminar na base de dados Scielo com busca integrada (com o termo "e/and") das palavras "Audiovisual", "Educação" e "Saúde" em $10 / 12 / 18$, foram encontrados 35 artigos sobre tais temáticas, sendo em sua maioria sobre produção de vídeos educativos com finalidades de integrar práticas pedagógicas com conhecimentos de saúde. Na base de dados do IBECS, foram encontrados 14 artigos articulando as temáticas supracitadas e nas bases de dados LILACS (123 artigos) e MEDLINE (199 artigos), pelo mesmo mecanismo de busca foram encontrados ao todo 322 artigos. Nota-se que existia um quantitativo relevante de artigos publicados e, neste sentido, este artigo propõe deixar uma contribuição complementar para o conjunto dos esforços científicos sobre a especificidade do contexto.

Diante deste contexto, foi evidenciada a seguinte situação-problema: como contribuir para o uso de tecnologias audiovisuais no desenvolvimento de habilidades e competências críticas de saúde e de educação entre adolescentes em uma instituição municipal de Assistência Social?

Com base nesta indagação, o presente artigo teve como objetivos contribuir para o desenvolvimento de habilidades e competências críticas de saúde e de educação entre adolescentes, com o uso de tecnologias audiovisuais, em uma instituição municipal de Assistência Social; bem como, sistematizar as propostas de ensino existentes que utilizem audiovisual e, analisar as propostas que articulem: audiovisual, saúde e educação em uma instituição municipal de Assistência Social.

\section{Metodologia}

Este estudo se configura no campo da pesquisa qualitativa em termos de abordagem, 
possuindo caráter exploratório quanto aos objetivos e transversal quanto ao tempo, com foco na interface entre saúde coletiva e políticas sociais, com especial vinculação aos estudos de Bosi (2012). Destaca-se, ainda, que o estudo possui características de pesquisa-ação em relação aos seus procedimentos propostos de acordo com os entendimentos consolidados nos estudos metodológicos de Silveira e Córdova (2009).

O campo de prática trata-se de um contexto de município do interior do estado do Ceará. O citado município possui cerca de 20 mil habitantes, distante aproximadamente 90 $\mathrm{Km}$ da capital Fortaleza.

As atividades citadas nesta pesquisa foram desenvolvidas na rotina de trabalho de uma instituição do município vinculada à Secretaria Municipal de Assistência Social, no ano de 2018. Este equipamento realiza atividades de fortalecimento de convivência e cidadania em parceria com diversos equipamentos públicos da cidade com o público de crianças e adolescentes.

Os sujeitos desta pesquisa foram: um coordenador, dois orientadores sociais instrutores de prática esportiva, um professor de informática e a colaboração de dez adolescentes. O critério de participação dos sujeitos foi o interesse em colaborar com o desenvolvimento das atividades de audiovisual em caráter experimental na instituição.

O planejamento, articulação e aplicação das etapas deste estudo-intervenção foi realizada pelo psicólogo da equipe técnica do CRAS. A função institucional da Psicologia é prestar apoio técnico aos professores e orientadores sociais, bem como realizar atendimentos e acompanhamentos dos adolescentes e seus familiares ao longo do ano. $O$ processo de planejamento, negociação institucional, execução e finalização de tarefas de implementação de práticas de audiovisual durou aproximadamente dois meses. Este processo de negociação teve alguns percalços, principalmente na articulação de datas disponíveis para reunir todos os sujeitos estratégicos para realização das oficinas. No que diz respeito à execução da pesquisa, esta foi dividida em duas etapas, sendo a primeira constituída de procedimentos preparatórios e a segunda constituída de três oficinas. Foi realizada uma oficina por semana com duração de uma hora e meia cada. (Figura 1).

A primeira etapa consistiu-se na sistematização dos principais conceitos e conteúdos oriundos do levantamento bibliográfico prévio a respeito da articulação entre saúde, educação e produção de audiovisual. Este levantamento foi composto pela seleção de cartilhas institucionais elaboradas pelo Ministério da Saúde, bem como de artigos científicos pertinentes ao tema deste estudo. Esta etapa subsidiou a elaboração das oficinas sobre saúde, educação e audiovisual que foram realizadas com os profissionais da instituição e com os adolescentes, posteriormente.

A segunda etapa constituiu-se da realização de três oficinas, nas quais foram trabalhadas as temáticas com os profissionais e os adolescentes que participaram das atividades da instituição. Cabe ressaltar que todas as oficinas foram realizadas por profissionais efetivos da instituição os quais trocaram experiências, ideias e aprendizados significativos com os sujeitos desta pesquisa.

A primeira oficina foi realizada em formato de roda de conversa mediada pelos seguintes temas geradores: acesso à saúde; lazer e educação na comunidade; cotidiano na comunidade e a percepção de se morar na comunidade. Embasou-se no referencial 
metodológico do formato do círculo de cultura proposto do Paulo Freire (1998). Em relação ao detalhamento do método do círculo de cultura elencado nesta oficina. É importante destacar os seguintes elementos:

\begin{abstract}
Tomando por princípio norteador o delineamento do "Método Paulo Freire", o desenvolvimento do Círculo de Cultura consiste de três momentos: a) a investigação temática, pela qual os componentes do círculo e o animador buscam, no universo vocabular dos participantes e da sociedade onde eles(as) vivem, as palavras e temas centrais de suas biografias; b) a tematização, mediante a qual eles(as) codificam e decodificam esses temas; ambos buscam o seu significado social, tomando assim consciência do mundo vivido; e c) a problematização, por meio de que eles(as) buscam superar a primeira visão mágica por uma visão crítica, partindo para a transformação do contexto vivido. (MONTEIRO e VIEIRA, 2009. p. 398).
\end{abstract}

Com base no entendimento acima, na primeira oficina, realizou-se um levantamento das principais dificuldades de trabalhar os temas de saúde na instituição e, posteriormente, realizou-se a sistematização dos temas relacionando saúde, educação e audiovisual. A discussão foi mediada por temas geradores e problematizadores, com auxílio de um facilitador, a respeito da estruturação de práticas de acolhimento, demandas de saúde no território, protocolos e rotinas de cuidado com os usuários, humanização, cuidado longitudinal e se tais temas foram alvos de produção de vídeos por parte dos adolescentes.

O resultado desta discussão foi sistematizado em um mural com as principais falas dos participantes e categorizado de acordo com o referencial da Análise de Conteúdo de Bardin (1977). O tipo de análise de conteúdo utilizada foi a análise temática que submete o material colhido aos procedimentos de pré-análise, exploração do material e tratamento dos resultados (inferência e interpretação). Estes procedimentos permitiram a criação de duas categorias centrais com subunidades temáticas. Cada categoria possui uma matriz contendo sua definição geral e as subunidades temáticas, também com definição, e os conteúdos percebidos em cada uma delas.

A segunda oficina consistiu na discussão e construção de roteiros dos vídeos com base nos temas oriundos da primeira oficina, bem como para a elaboração de estratégias coletivas com vistas à construção de vídeos críticos sobre os principais problemas de saúde e sociais percebidos na comunidade (COSTA, 2016). As oficinas de construção de roteiros foram feitas em dois grupos de cinco adolescentes mediados por profissionais da instituição. As modalidades de construção de vídeos estavam abertas as mais diversas possíveis tais como simulações de talk-shows, entrevistas de bancada tele jornalística, reportagem de rua, musical, entre outras. Este tipo de proposta de construir conhecimento ao mesmo tempo em que se age diante da realidade pesquisada possui traços relevantes de pesquisa-ação conforme se nota nos elementos teóricos trazidos por Toledo et al (2014):

\footnotetext{
A pesquisa-ação, por ser uma metodologia aberta e dinâmica, permite que diferentes rumos sejam tomados no decorrer do seu desenvolvimento, em função das demandas encontradas. Isso ocorre porque o envolvimento direto de representantes da problemática em todas etapas desse processo, com suas necessidades, anseios, valores e saberes, irá interferir em adequações metodológicas. (p. 638)
}

Ainda segundo o entendimento acima, esta modalidade de pesquisa permite a construção de conhecimentos com as seguintes características: $1^{\circ}$ ) metodologia dinâmica, 
com adequações no decorrer do processo de investigação e intervenção; $2^{\circ}$ ) combinação de múltiplos instrumentos de pesquisa e intervenção; e $3^{\circ}$ ) participação e cooperação dos/e entre sujeitos e pesquisadores. Estas características foram fundamentais para superar as dificuldades do campo, tais como as dificuldades de articular agenda entre os participantes e a escassez de materiais da instituição para trabalhar com audiovisual. A flexibilidade de utilização de diversos métodos-ação articulados permitiu a viabilidade das duas primeiras oficinas e a execução da terceira.

Na terceira oficina, foi realizada a gravação do vídeo propriamente dito e foram feitas as edições dos mesmos. Para a produção de vídeos, a mesma equipe da produção de roteiro foi preservada (um coordenador, dois orientadores sociais - instrutores de prática esportiva, um professor de informática, colaboração e dois grupos de cinco adolescentes em cada) de forma a permitir uma aprendizagem contínua. A mediação de cada grupo foi processual para auxiliar na construção de cada subproduto e do produto final em cada semana. As oficinas ocorreram de forma articulada com as atividades regulares já programadas para os adolescentes e, neste sentido, a articulação com os orientadores, professores e instrutores foi fundamental.

Como já mencionado, o município possui dificuldades de acesso à Internet nas instituições. Neste sentido, utilizou-se os recursos de criação e edição básica de vídeo por meio de aplicativos que usavam câmeras de celular (resolução mínima de 1,2MP), sistema Android, para realização da segunda e terceira oficinas. Para finalização dos vídeos, foi utilizado o software Windows Movie Maker (versão 12 16.4.3528.0331), no laboratório de informática, para inclusão de imagens, som e legendas. A figura 1 mostra o fluxograma com o resumo das propostas das oficinas.

Figura 1: Fluxograma das oficinas de construção de vídeos.

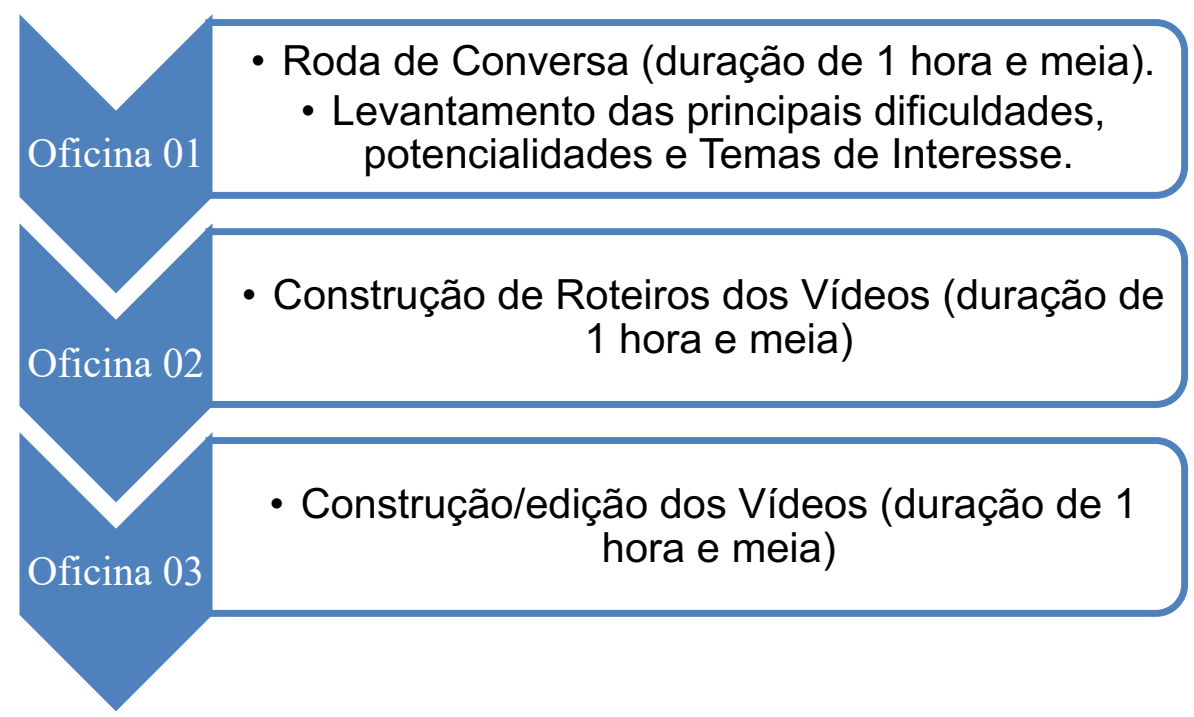

Fonte: elaboração própria.

Ao final das atividades, cada grupo passou pelo processo completo de produção de conteúdo que consistiu na: elaboração do roteiro, gravação do vídeo, edição básica do vídeo no smartphone, edição final do vídeo no computador e publicação do vídeo em uma mídia social, a fim de concluir pelo menos um vídeo e socializar-se com os demais grupos. 
Entende-se que a metodologia de realização deste ciclo de construção de audiovisual por parte dos adolescentes, em colaboração com os adultos, pôde contribuir para o desenvolvimento de uma consciência colaborativa sobre o ato de produzir os vídeos e seus conteúdos como apontam os estudos de Cruz (2016):

Os encontros realizados e os registros obtidos oferecem muitas possibilidades de reflexão sobre os usos dos espaços digitais pelos adolescentes e jovens. Conhecer esses usos oferece a oportunidade de uma aproximação com os alunos que estão na escola, conhecendo-os um pouco melhor. Este conhecimento pode ajudar a planejar, repensar e implementar práticas que favoreçam o desenvolvimento dos alunos não só dentro da escola, mas também enquanto cidadãos que atuam e convivem numa cultura digital, dentro de espaços on-line e off-line. (p. 80)

Embora este estudo tenha ocorrido fora do ambiente escolar clássico, os apontamentos da autora acima são válidos, pois, na instituição de assistência social também se desenvolvem processos de ensino-aprendizagem entre os partícipes das atividades de cidadania e das oficinas de construção de audiovisual.

Em relação aos aspectos éticos desta iniciativa, trata-se de um estudo que objetiva o aprofundamento teórico de situações que emergem contingencialmente na prática profissional amparada pelo item VII do art $1^{\circ}$ da Resolução $n^{\circ} 510$, de 07 de abril de 2016 (normas aplicáveis a pesquisas em Ciências Humanas e Sociais) do Conselho Nacional de Saúde, sendo preservados o sigilo e confidencialidade dos sujeitos.

\section{Resultados e Discussão.}

Relevante salientar que a observação preliminar do campo permitiu perceber que havia interesse dos adolescentes em trabalhar de forma organizada com a produção de audiovisual a respeito de diversos aspectos do seu cotidiano. Este interesse pôde ser notado pelo fato de que entre dez adolescentes que participaram das atividades, seis deles já tinham gravado vídeos amadores em outras oportunidades (vídeos sobre divulgação de festas de interesse deles na comunidade, vídeos curtos com posicionamento político sobre a situação da cidade e vídeos de momentos de diversão e humor com uma turma de amigos). Este interesse percebido forneceu ao cenário para a pesquisa-ação de que a realização das oficinas sobre audiovisual poderia significar uma excelente oportunidade para discutir subjetividade, identidade e percepção de realidade dos adolescentes conforme apontam os estudos de Conti et al (2010):

A adolescência, compreendida como uma construção social moderna, representa uma possibilidade de emergência da subjetividade com novas referências e padrões identitários (SERRA, 2003). Particularmente para os adolescentes, os meios de comunicação contribuem inegavelmente para um aprendizado sobre modos de comportar-se, sobre modos de constituir-se a si mesmo (FISCHER, 2002). (p. 2096)

Neste contexto, havia uma oportunidade de discutir os diversos processos de saúde em sua complexidade, seja de humanização, acolhimento (BRASIL, 2004) ou cuidado (AYRES, 2004), em permanente diálogo com as contradições do território (SANTOS, 1985) em que vivem.

Os resultados da discussão realizada na primeira oficina foram organizados em duas 
categorias fruto das etapas da metodologia de refinamento da Análise de Conteúdo. As categorias são: "dificuldades e o processo de denúncia do não acesso à saúde e educação" (Quadro 1), "o processo de construção de visibilidade da comunidade" (Quadro 2). A seguir, há a primeira matriz sintética de categoria chamada de "dificuldades e o processo de denúncia do não acesso à saúde e educação" (Quadro 1).

Quadro 1: Matriz sintética da categoria: dificuldades e o processo de denúncia do não acesso à saúde e educação.

\begin{tabular}{|c|c|}
\hline \multicolumn{2}{|r|}{ Matriz Sintética de Descrição de Resultados Encontrados } \\
\hline \multicolumn{2}{|c|}{ Categoria: Dificuldades e o processo de denúncia do não acesso à saúde e educação. } \\
\hline \multicolumn{2}{|c|}{$\begin{array}{l}\text { Definição: esta categoria se configura enquanto representação dos conteúdos em que } \\
\text { prevalecem as evidências de que os adolescentes percebem que sua condição social é } \\
\text { composta cotidianamente por uma série de dificuldades de acesso à saúde e educação e que } \\
\text { precisam ser evidenciadas para que haja mudança. }\end{array}$} \\
\hline Temas & Exemplos de Conteúdos Temáticos Significativos \\
\hline $\begin{array}{l}\text { Precarização das } \\
\text { políticas públicas de } \\
\text { saúde e educação no } \\
\text { bairro }\end{array}$ & $\begin{array}{l}\text { S1: "Falta tudo no posto de saúde" } \\
\text { S3: "Minha escola não tem internet" } \\
\text { S5: "Devia melhorar a merenda e devia ter mais arte pra gente" }\end{array}$ \\
\hline $\begin{array}{l}\text { Esquecimento do } \\
\text { bairro e reforma } \\
\text { oportunista de } \\
\text { equipamentos } \\
\text { públicos }\end{array}$ & $\begin{array}{l}\text { S2: "vereador só vem aqui em época de eleição e diz que vai ajeitar as } \\
\text { coisas, mas nós sabe (sic) que não vão ajeitar" } \\
\text { S3: "Quando a reportagem vem, a gente diz mesmo que está faltando } \\
\text { tudo". } \\
\text { S4: "A gente filma e bota no face (Facebook) também" }\end{array}$ \\
\hline
\end{tabular}

Fonte: elaboração própria.

Nota-se nos temas da categoria acima que surgiram diversas questões relativas às condições de negação de direitos sociais fundamentais da cidadania, como a saúde e educação. No que diz respeito à política pública de saúde, os estudos de Vasconcelos e Pasche (2009) demonstram que a estruturação do Sistema Único de Saúde (SUS) é historicamente carregada de contradições (avanços e retrocessos) e que, em muitas ocasiões, a negação do direito à saúde para a população que mais necessita produz uma série de iniquidades sociais. Já os estudos de Marques, Santos e Júnior (2014) demonstram a importância dos serviços de proteção social para melhoria da qualidade de vida de famílias e indivíduos. Neste sentido, o contexto de negação de acesso aos direitos tidos como fundamentais, tais como educação e saúde, pode representar uma série de perdas no desenvolvimento destes sujeitos.

A percepção dos adolescentes é de que há políticas públicas, contudo, estas estão precarizadas e funcionam com dificuldades. Um dos conflitos existentes nesta etapa consistiu no fato de que alguns adultos (orientadores e professores) presentes na roda de conversa divergiram dos adolescentes no sentido de que eles estavam se negando a enxergar que, também, há elementos positivos nas políticas públicas do município. Após breve debate a respeito da discordância acima citada, não houve acordo entre adolescentes e adultos sobre estas percepções a respeito das políticas públicas da cidade. Estas questões apareceram nos materiais elaborados na oficina e foram um eixo marcante de 
percepção dos adolescentes e dos profissionais que participaram. Além do reconhecimento destas falhas nos serviços públicos, existe um entendimento de que um dos mecanismos de cobrança é a produção de vídeos, seja pela imprensa convencional ou pelas mídias alternativas em redes sociais, tais como o Facebook.

A possibilidade do uso de múltiplas ferramentas digitais pelos adolescentes permite o acesso a um universo de possibilidades de comunicação de seus pensamentos, suas ideias e suas eventuais denúncias sobre a negação de seus direitos. Os adolescentes possuem uma certa consciência do seu poder de uso das redes sociais e que os vídeos podem atingir um grande público, conforme fica nítido nas seguintes falas: S3: "Quando a reportagem vem, a gente diz mesmo que está faltando tudo". S4: "A gente filma e bota no face (Facebook) também". O Facebook neste caso é apenas uma das plataformas utilizáveis, podendos os adolescentes acessarem outras plataformas para dar vazão a sua voz, conforme apontam os estudos de Cruz (2016):

A simultaneidade e a convergência de mídias estão presentes na vida desses jovens
e os recursos digitais são acessados por meio da Internet com tal naturalidade que
estão redefinindo os modos de interação entre os usuários. Formas diversas de
comunicação, através de mensagens, imagens ou dos vídeos on-line, já se tornaram
uma nova forma de escrita e de comunicação via web, oportunizadas pelos
aparelhos móveis com incontáveis recursos, editores de vídeos ou imagens e
aplicativos cada vez mais inovadores. A facilidade de conexão dos usuários, aliada
às práticas culturais e sociais contemporâneas, torna o cenário midiático e os
relacionamentos virtuais muito interativos e atrativos, principalmente para o público
jovem que, segundo as pesquisas descritas, compõe o grande número de usuários
da web. Assim, é possível afirmar que todo esse aparato tecnológico acessível e
híbrido influencia os modos de ser, de compreender e de se relacionar dos jovens da
contemporaneidade. (p. 25$)$

Importante ressaltar que a utilização de vídeos no processo de interface entre os campos da saúde e da educação pode ser uma ferramenta muito potente como demonstram Lima et al (2017) e Costa et al (2016), reforçados pelos estudos de Dalmolin et al (2017):

os vídeos educativos têm sido utilizados em diversas experiências pedagógicas demonstrando a relevância da sua aplicabilidade no processo de ensino aprendizagem, pois combinam vários elementos, tais como imagens, texto e som em um único objeto de promoção do conhecimento. (p. 2)

Esta noção crítica emitida nos conteúdos dos adolescentes e de alguns profissionais vão ao encontro dos achados existentes nos estudos de Hebenbrock (2019) no sentido de que o audiovisual pode ser uma ferramenta poderosa de denúncia e de luta social por melhorias, bem como de ressignificação de identidades e de subjetividades. Restava saber se estas percepções emitidas na primeira oficina iriam se materializar nas próximas etapas de construção dos vídeos.

A segunda categoria elaborada foi "o processo de construção de visibilidade da comunidade" e o seu detalhamento se encontra na matriz sintética a seguir (Quadro 2).

Quadro 2: Matriz sintética da categoria: o processo de construção de visibilidade da comunidade.

Matriz Sintética de Descrição de Resultados Encontrados 


\begin{tabular}{|c|c|}
\hline \multicolumn{2}{|c|}{ Categoria: o processo de construção de visibilidade da comunidade. } \\
\hline \multicolumn{2}{|c|}{$\begin{array}{l}\text { Definição: Esta categoria se configura enquanto representação dos conteúdos em que } \\
\text { prevalecem as evidências de que os adolescentes percebem que eles podem ter voz ativa e } \\
\text { que dar visibilidade à comunidade pode construir uma identidade coletiva. }\end{array}$} \\
\hline Temas & Exemplos de Conteúdos Temáticos Siqnificativos \\
\hline $\begin{array}{c}\text { A comunidade é um } \\
\text { lugar com múltiplas } \\
\text { percepções a serem } \\
\text { vistas. }\end{array}$ & $\begin{array}{l}\text { S3: "Tem muita gente errada, tem coisa feia, mas tem coisa legal } \\
\text { também. As festa (sic) na escola, a gente gosta, mas não aparece } \\
\text { para todos mundo como uma coisa boa" } \\
\text { S2: "Minha mãe não gosta daqui, mas eu gosto. Eu gosto do pessoal } \\
\text { do Posto de Saúde, cuidam bem da minha irmã lá e eu não tenho que } \\
\text { reclamar" }\end{array}$ \\
\hline $\begin{array}{l}\text { Visibilidade Seletiva } \\
\text { da Comunidade }\end{array}$ & $\begin{array}{l}\text { S4: "Quando morre alguém, aparece tudo que é de jornal aqui. Galera } \\
\text { bota na Internet e tal. Quando tem inauguração de pintura de escola } \\
\text { também aparece na internet. Mas as meninas quando tiram nota boa } \\
\text { não tem um reconhecimento" } \\
\text { S1: "Quando a reportagem vem, a gente diz mesmo que está faltando } \\
\text { tudo". } \\
\text { S5: "A gente gosta quando um vídeo da gente bomba na Internet. } \\
\text { Temo (sic) orqulho de mostrar o que tem de bom aqui" }\end{array}$ \\
\hline
\end{tabular}

Fonte: elaboração própria.

É possível notar nesta segunda categoria demonstrada na matriz (quadro 2) anterior e nos subtemas que emergiram conteúdos de percepção de que o território em que vivem os adolescentes é um complexo ambiente com múltiplas percepções (positivas e negativas). Este território pode ser ressignificado, replanejado e reconstruído, inclusive levando-se em consideração as diretrizes previstas nos estudos de Paim (2006). Este entendimento de que os territórios são o conjunto de múltiplos fatores sociais e políticos está alinhado com os aspectos fornecidos pelos estudos de Santos (1985).

Os temas geradores iniciais (acesso à saúde, lazer e educação na comunidade; cotidiano na comunidade e a percepção de se morar na comunidade) da primeira oficina desencadearam uma discussão produtiva sobre percepção do lugar onde os adolescentes vivem, bem como certa consciência de que podem lutar por melhorias e o audiovisual poder ser um caminho viável. Neste sentido, os adolescentes expressaram que sabem do potencial de alcance e engajamento dos vídeos por eles produzidos, conforme demonstrase na fala a seguir: S5: "A gente gosta quando um vídeo da gente bomba na Internet. Temo (sic) orgulho de mostrar o que tem de bom aqui". Estas percepções vão ao encontro dos dados obtidos nos estudos de Almeida (2013):

Nesse sentido, quando se conhece - mesmo que minimamente - esse aporte teórico, percebe-se sua adequação às práticas sociais dos aprendizes da atualidade que, mais do que em outros tempos, trabalham colaborativamente em seus blogs, wikis e trocas de arquivos, facilitadas pelas conexões banda-larga; da mesma forma, quando produzem seus vídeos sobre os mais variados temas e dão visibilidade a tais produções, via YouTube, ignoram possíveis críticas e avaliações que poderiam taxálos como "não publicáveis"; ainda, a terceira característica pode ser vista através da gama de saberes que é trocada, intercambiada e mesclada em atividades, como nos jogos em rede, por exemplo. (p.07)

A segunda oficina obteve como resultados a produção de dois roteiros, sendo um roteiro por cada equipe. Um dos roteiros focou mais em conteúdos relativos sobre a necessidade de fortalecer as práticas de esporte na comunidade, evidenciando que naquele 
território havia muitos potenciais atletas, bem como havia possibilidade de articular esse espaço de visibilidade com a organização de campeonatos locais de futebol (nas escolas e campos de futebol existentes) e o vídeo poderia servir para chamar a população para participar. O segundo roteiro versou sobre uma proposta de reportagem mostrando o abandono do poder público na comunidade, sobretudo nos aspectos de saneamento básico e sucateamento dos equipamentos de saúde e educação. Foi sugerido que também fosse levado em consideração o que havia de positivo para que os adolescentes fizessem o exercício de pensar o contraditório. Uma dificuldade encontrada na oficina de roteiros foi a barreira da organização da escrita, pois os adolescentes conseguiam trazer boas ideias e não conseguiam as escrever em um roteiro simples. Este fato traz luz para uma realidade que precisa ser encarada em sua complexidade que é a alfabetização precária no sistema educacional.

O resultado da terceira oficina foi o aumento do conhecimento sobre as possibilidades do uso de Tecnologias Digitais de Informação e Comunicação (TDICs) no processo de ensino e aprendizagem. Neste caso, em específico, as tecnologias que já vinham sendo utilizadas, como os smartphones, com os propósitos orientados de produção de audiovisual. Ou seja, os adolescentes e os trabalhadores da instituição percebiam que a produção de vídeos educativos, com intencionalidade de debater os diversos temas da saúde em interface com a educação poderiam ser uma ferramenta potente de aprendizado crítico conforme subsídios fornecidos por Dalmolin et al (2017) e por Cruz (2016):

Diante do que foi apresentado, há também autores que entendem essa potencialidade de produção e exibição impulsionada pelas tecnologias como algo significativo, que valoriza a capacidade de os usuários produzirem e manifestarem suas opiniões, desejos e ideias dos espaços digitais. Couto (2014) destaca que, agora, o discurso público é construído por meio de ampla participação, com conteúdos variados, produzidos e compartilhados, e complementa que existem possibilidades de aprendizado contínuo com e nas redes sociais digitais. Esses novos usuários da internet são essencialmente colaboradores em diversos aspectos, "são ativistas, querem compartilhar e fazer juntos" (p. 79).

Como desdobramento do entendimento acima citado, ficou evidente que a realização destas oficinas com caráter interventivo e participativo, mesmo que tenham ocorrido em caráter experimental e focal para apresentar uma proposta de trabalho, foram relevantes para que os adolescentes percebessem que são sujeitos ativos de sua história e que pode melhorar a qualidade de conteúdo e a técnica de suas produções de audiovisual. Importante destacar que os estudos de Belloni e Gomes (2008) apontam que a construção conjunta de conhecimento ajuda a desenvolver habilidades de leitura crítica de realidade como a que se percebeu com os adolescentes deste estudo:

Vigotski, por sua vez, enfatiza que a construção do conhecimento ocorre em ambientes influenciados pela ação do sujeito sobre o meio e pelas mediações entre ele e seus pares, que favorecem o desenvolvimento de processos mentais superiores quando empregados num ciclo que pressupõe descrição-execuçãoreflexão-depuração de ideias na resolução de problemas (Valente, 1993). Para Vigotski (1987, p. 17), “(...) a colaboração entre pares durante a aprendizagem pode ajudar a desenvolver estratégias e habilidades gerais de solução de problemas através da internalização do processo cognitivo implícito na interação e na comunicação" (p. 729). 
Do ponto de vista institucional, as intervenções realizadas contribuíram para a abertura de possibilidades concretas de utilização do audiovisual nas atividades de cidadania como uma ferramenta potente e que pode produzir um alcance grande de visibilidade nas redes sociais. Além deste aspecto acima citado, é importante frisar que estas oficinas contribuíram para que uma parte da instituição escutasse mais os adolescentes no que eles tinham a dizer sobre sua realidade.

Adicionalmente, foi organizada uma apresentação de vídeos produzidos pelos adolescentes com a presença dos professores, equipe técnica do CRAS (psicólogo) e orientadores sociais que participaram do processo de construção. Nesta exibição foram disponibilizados dois vídeos produzidos como resultado final das oficinas. Os vídeos tinham de três minutos de duração em sua versão final e os adolescentes falavam no primeiro vídeo sobre esporte (com foco no futebol) na comunidade e seus sonhos sobre esta temática e, no segundo vídeo, a temática era mais voltada para a percepção da vida deles na comunidade. Este espaço de visibilidade dialogada foi um importante passo para integração de todos os envolvidos, além de ser uma oportunidade de incentivo a diversos talentos existentes nos bairros do município fortalecendo a territorialidade.

A implementação de um processo de produção de vídeos sobre temáticas de interface entre saúde, educação de forma dialógica e permanente produz mudanças nos processos de trabalho das instituições. Estas mudanças podem, inclusive, mexer e, de fato, mexeram nas zonas de conforto dos profissionais, haja vista que alteram rotinas de atividades e exigem a participação ativa.

Mesmo diante deste risco de tensionamento no serviço, foi preciso vencer esta barreira e o primeiro resultado desta iniciativa consistiu em contribuir para a promoção de mudanças nas agendas das equipes e dos profissionais. Estas mudanças nos processos de trabalho foram necessárias para construção dos fluxos, bem como necessárias para manutenção destes fluxos de ensino e aprendizagem em consonância com os PCNs preconizadas por Brasil (1998). Importante salientar que esta implementação experimental da produção de vídeos permitiu evidenciar a fragilidade das propostas de ensino existentes na instituição que utilizaram o audiovisual. Tornar este aspecto acima citado visível produziu um certo desconforto na instituição pois a elucidação de fragilidades ainda não é um ato bem visto na cultura dos processos de trabalho.

Estas mudanças dentro da instituição e entre a instituição e os outros equipamentos da rede fortalecem os princípios da intersetorialidade e da construção de uma perspectiva ampliada da clínica conforme preconizam as orientações de Brasil (2004). Caso a instituição queira vivenciar, por meio do incentivo à construção de vídeos educativos de seus adolescentes, a complexidade do SUS, do SUAS e do Sistema de Educação, terá que praticar o conceito da intersetorialidade no seu dia a dia.

O último resultado foi a criação de uma rede minimamente articulada de colaboração entre adolescentes, docentes, gestores e comunidade. Esta rede ainda funciona de forma precária, mas esta iniciativa foi um pequeno passo para que esta experiência servisse como motivadora de uma ampliação de práticas de integração entre os serviços pela via do cuidado (AYRES, 2004), uma vez que os usuários transitam por todos os serviços públicos 
municipais, principalmente, um fluxo junto à Estratégia Saúde da Família e aos demais equipamentos (ANDRADE, BARRETO E BEZERRA,2009).

\section{Conclusão}

A construção do conhecimento a partir da realidade de trabalho do próprio pesquisador é uma iniciativa bastante complexa e multifacetada. Este é um dos cenários dos quais se desdobram das particularidades de se fazer pesquisa-ação elencada por Toledo et al (2014).

Importante destacar que as instituições públicas mencionadas neste estudo sofrem com a alta rotatividade de profissionais, bem como as mudanças de gestão da prefeitura e de coordenação do serviço. Estes aspectos que constituem uma parte da precarização dos serviços apontada pelos participantes das oficinas precisam ser refletidos de forma crítica e contextualizada pela instituição, pelos gestores e pelos profissionais que a compõem. Por estas razões, foi desafiador o desenvolvimento de atividades de audiovisual neste contexto. Contudo, tais dificuldades serviram de aprendizado sobre a importância de apreender a lidar rapidamente com as mudanças que ocorrem nos equipamentos públicos da cidade.

Os adolescentes adquiriram uma série de conhecimentos de forma organizada nas oficinas em que participaram. Houve incentivo para que houvesse o debate sobre os problemas existentes em seu cotidiano e articular minimamente tal contexto na discussão sobre acesso a saúde e educação.

A construção dos roteiros e dos vídeos em si tornaram o aprendizado de habilidades de escrita, leitura, criação e interpretação mais significativas, embora se perceba a dificuldade nestas habilidades e competências em alguns adolescentes. Mesmo com estas dificuldades acima citadas, o uso de tecnologias digitais na produção dos vídeos, incentivado pela realização das oficinas, contribuiu para despertar a curiosidade dos adolescentes para aprender a ler e escrever melhor, bem como contribuiu para desenvolver criticidade na percepção de realidade nos adolescentes conforme apontam os estudos de Belloni e Gomes (2008).

Em relação a análise da proposta deste estudo quanto a contribuição para o desenvolvimento de habilidades e competências críticas de saúde e de educação (por exemplo: o conhecimento de como funcionam estas política públicas e quais são os direitos que os sujeitos podem acessar) entre adolescentes, com o uso de tecnologias audiovisuais, em uma instituição municipal de Assistência Social, foi possível observar que os resultados deste estudo demonstraram que houve aprendizado de novas habilidades e competências por parte dos adolescentes na organização de percepção crítica sobre seus direitos sociais, bem como no aprendizado de uso de novas ferramentas de tecnologia da informação e comunicação para produção de audiovisual. A ampliação deste conhecimento sobre o uso das ferramentas e a ampliação de leitura crítica de realidade pelos adolescentes estão em harmonia com a literatura nesta área, principalmente, os estudos de Dalmolin et al (2017), por Cruz (2016) e Almeida (2013).

No tocante a sistematização das propostas de ensino existentes que utilizem audiovisual, ficou evidenciado que há uma precariedade das propostas existentes. Ainda 
pertinente a esta análise, os resultados do estudo certificaram que não havia cultura de utilização organizada de audiovisual entre os adolescentes que participaram da rotina de atividades. Sendo assim, este estudo se apresenta como pioneiro na proposição deste tipo de prática de aprendizado. Ao demonstrar que é possível realizar atividades de produção de audiovisual com os poucos recursos disponibilizados pela instituição no cotidiano, este estudo deixa como contribuição significativa a abertura de caminhos para a implementação do uso do audiovisual como uma estratégia de desenvolvimento de criticidade pelos adolescentes.

A partir da análise das propostas que articulem: audiovisual, saúde e educação na instituição, considerou-se que a iniciativa deste estudo caminhou no sentido de propor ações de intervenção para produção de audiovisual, relacionando educação e saúde na instituição, evidenciando que esta intencionalidade foi alcançada na medida em que a proposição das oficinas atingiu o cumprimento da apresentação desta iniciativa-piloto da produção de audiovisual nas atividades da instituição.

Espera-se que este estudo subsidie os gestores do município em tela quanto à necessidade de dotar a instituição, campo empírico deste estudo, com Internet banda larga, compra de equipamentos adequados para o audiovisual, pois estes atos poderiam ampliar as possibilidades de uso das tecnologias de produção, edição e postagem de vídeos educativos protagonizados pelos adolescentes do município.

Percebe-se que há um potencial enorme de desenvolvimento de atividades de largo alcance social em diversas comunidades vulneráveis que dependem da prestação de serviços de instituições de assistência social. Neste seguimento, sendo possível que caso uma instituição venha a desenvolver um projeto que articule saúde, educação e uso de tecnologias audiovisuais, é provável que se observem mudanças ao longo do tempo na instituição adotante e que estas contribuam para uma efetiva melhoria de processos.

\section{Referências}

ALMEIDA, Ana Cláudia Pereira de. Produção de vídeos em sala de aula: uma proposta de uso pedagógico de celulares e câmeras digitais. Tear: Revista de Educação Ciência e Tecnologia, Canoas, v.2, n.1, 2013. Disponível em:

http://www.pucrs.br/ciencias/viali/recursos/offline/videos/111-738-1-PB.pdf. Acesso em 16 ago. 2020.

ANDRADE, L.O.M de; BARRETO, I.C. de H.C; BEZERRA, R.C. Atenção primária a saúde e estratégia de saúde da família. IN: CAMPOS, G. W. de S. Tratado de saúde coletiva. São Paulo: Hucitec, 2009. p. 783-836.

ARAÚJO, S.S. de; AGUIAR NETO, A.O; GOMES, L.J. A percepção ambiental, identidade e pertencimento dos moradores do povoado Cabeço, em Brejo Grande/SE, frente às inundações na foz do rio São Francisco. Desenvolv. Meio Ambiente, v. 36, p. 239-253, abr. 2016. Disponível em: https://revistas.ufpr.br/made/article/view/37818/27914 Acesso em: 20 fev. 2019. DOI: http://dx.doi.org/10.5380/dma.v36i0.37818

AYRES, José Ricardo de Carvalho Mesquita. O cuidado, os modos de ser (do) humano e as práticas de saúde. Saúde Soc., São Paulo, v. 13, n. 3, p. 16-29, dez. 2004. Disponível em <http://www.scielo.br/scielo.php?script=sci_arttext\&pid=S0104- 
$12902004000300003 \&$ Ing=pt\&nrm=iso>. Acesso em: 10 fev. 2019.

https://doi.org/10.1590/S0104-12902004000300003.

BARDIN, L. Análise de conteúdo. Lisboa: Edições 70; 1977.

BELLONI, Maria Luiza; GOMES, Nilza Godoy. Infância, mídias e aprendizagem: autodidaxia e colaboração. Educ. Soc., Campinas, v. 29, n. 104, p. 717-746, Oct. 2008. Disponível em: $<$ http://www.scielo.br/scielo.php?script=sci_arttext\&pid=S0101-

$73302008000300005 \&$ Ing=en\&nrm=iso>. Acesso em 16 Ago. 2020.

https://doi.org/10.1590/S0101-73302008000300005

BOSI, Maria Lúcia Magalhães. Pesquisa qualitativa em saúde coletiva: panorama e desafios. Ciênc. Saúde Coletiva, Rio de Janeiro, v. 17, n. 3, p. 575-586, Mar. 2012.

Disponível em: <http://www.scielo.br/scielo.php?script=sci_arttext\&pid=S1413-

81232012000300002\&lng=en\&nrm=iso>. Acesso em: 06 Fev 2019.

http://dx.doi.org/10.1590/S1413-81232012000300002.

BRASIL. Ministério da Educação. Parâmetros curriculares nacionais: saúde. Brasília, DF, 1998. Disponível em: http://portal.mec.gov.br/seb/arquivos/pdf/saude.pdf . Acesso em: 27 dez. 2017.

BRASIL. Ministério da Saúde. Secretaria-Executiva. Núcleo Técnico da Política Nacional de Humanização. Humaniza SUS: acolhimento com avaliação e classificação de risco: um paradigma ético-estético no fazer em saúde / Ministério da Saúde, Secretaria-Executiva, Núcleo Técnico da Política Nacional de Humanização. Brasília: Ministério da Saúde, 2004. CONTI, Maria Aparecida; BERTOLIN, Maria Natacha Toral; PERES, Stela Verzinhasse. A mídia e o corpo: o que o jovem tem a dizer?. Ciência \& Saúde Coletiva, 15(4):2095-2103, 2010. Disponível em: https://www.scielosp.org/pdf/csc/2010.v15n4/2095-2103/pt Acesso em: Acesso em 16 ago. 2020.

COSTA, Tarcila Lima da et al. Material multimídia para orientação dos cuidadores de bebês com fissura labiopalatina sobre velofaringe e palatoplastia primária. CoDAS, São Paulo, v. 28, n.1,p. 10-16, Fev. 2016. Disponível

em:<http://www.scielo.br/scielo.php?script=sci_arttext\&pid=S2317-

$17822016000100010 \&$ Ing=en\&nrm=iso>. Acesso em: 21 Out 2018.

http://dx.doi.org/10.1590/2317-1782/20162014126.

CRUZ, Andréa Otoni Antunes Sales da. Interação dos jovens a partir das mídias digitais: implicações no cotidiano escolar. 2016. Dissertação. (Mestrado em Educação).

Faculdade de Educação, Universidade Federal de Juiz de Fora, Juiz de Fora, Minas Gerais, 2016. Disponível em: https://www.ufff.br/ppge/files/2018/06/Disserta\%C3\%A7\%C3\%A3oAndrea-Otoni-PosDefesa.pdf Acesso em 16 ago. 2020.

DALMOLIN, Angélica et al. Vídeo educativo como recurso para educação em saúde a pessoas com colostomia e familiares. Rev. Gaúcha Enferm. Porto Alegre, v. 37, n. spe, e68373, 2016. Disponível em:

$<$ http://www.scielo.br/scielo.php?script=sci_arttext\&pid=S1983-

14472016000500408\&Ing=en\&nrm=iso>. Acesso em: 20 jun de 2018 Epub Apr 06, 2017.

http://dx.doi.org/10.1590/1983-1447.2016.esp.68373

FREIRE, Paulo. Pedagogia da autonomia: saberes necessários à prática educativa. 7. ed.

Rio de Janeiro: Paz e Terra, 1998. 
HEBENBROCK, J.M da S. O Audiovisual como denúncia social. VII Encontro Nacional de História da Mídia. Disponível em: http://www.ufrgs.br/alcar/encontros-nacionais1/encontros-nacionais/7o-encontro-2009

1/O\%20Audiovisual\%20como\%20denuncia\%20social.pdf. Acesso em 15 de março de 2020. LIMA, Marília Brito de et al. Construção e validação de vídeo educativo para orientação de pais de crianças em cateterismo intermitente limpo. Rev. Esc. Enferm. USP, São Paulo, v. 51, e03273, 2017. Disponível em:

http://www.scielo.br/scielo.php?script=sci_arttext\&pid=S0080-

62342017000100462\&Ing=en\&nrm=iso. Acesso em: 20 Fev 2020. Epub Dec 18, 2017. https://doi.org/10.1590/s1980-220x2016005603273.

LOUREIRO, Carlos Frederico B.; FRANCO. Jussara Botelho. Aspectos teóricos e metodológicos do círculo de cultura: uma possibilidade pedagógica e dialógica em educação ambiental. Ambiente \& Educação. vol. 17(1), 2012. Disponível em:

https://periodicos.furg.br/ambeduc/article/view/2422/1666 Acesso em: 20 Fev 2019. MARQUES, Douglas; SANTOS, Everton Rodrigo; JUNIOR, Norberto Kuhn. Sistema Único de Assistência Social (SUAS) e descentralização político-administrativa: entre a (in) eficiência administrativa e a (in) operância política. Pensamento Plural. Pelotas [15]: 71 89, julho-dezembro 2014.Disponível em:

https://periodicos.ufpel.edu.br/ojs2/index.php/pensamentoplural/article/view/4621/3963.

Acesso em: 20 Mar 2020. DOI: http://dx.doi.org/10.15210/PP.V0I15.4621

MONTEIRO, Estela Maria Leite Meirelles; VIEIRA, Neiva Francenely Cunha. Educação em saúde a partir de círculos de cultura.Rev. Bras. Enferm., Brasília ,v. 63, n. 3, p. 397-403, June 2010. Disponível em:<http://www.scielo.br/scielo.php?script=sci_arttext\&pid=S003471672010000300008\&lng=en\&nrm=iso>. Acesso em: 13 Ago 2020.

http://dx.doi.org/10.1590/S0034-71672010000300008.

PAIM, J. S. Planejamento em Saúde para não Especialistas. In: CAMPOS, G. W. de S.

Tratado de saúde coletiva. São Paulo: Hucitec, 2006. p.767-782

ROSADO, Luiz Alexandre da Silva; TOME, Vitor Manuel Nabais. As redes sociais na internet e suas apropriações por jovens brasileiros e portugueses em idade escolar. Rev.

Bras. Estud. Pedagog., Brasília, v. 96,n. 242, p. 11-25, abr. 2015. Disponível em

$<$ http://www.scielo.br/scielo.php?script=sci_arttext\&pid=S2176-

66812015000100011\&lng=pt\&nrm=iso>. Acesso em: 13 Ago 2020.

https://doi.org/10.1590/S2176-6681/324612565

SANTOS, Milton. Espaço e método. São Paulo: Nobel, 1985.

SILVEIRA, D.T; CÓRDOVA, F.P. Unidade 2 - A pesquisa científica. In: GERHARDT, E;

SILVEIRA, D.T (Org). Métodos de pesquisa. Porto Alegre: Editora da UFRGS, 2009.

Disponível em:

https://lume.ufrgs.br/bitstream/handle/10183/52806/000728684.pdf?sequence=1\&isAllowed= y Acesso em 15 Fev 2019.

TOLEDO, Renata Ferraz de, GIATTI, Leandro Luiz e Jacobi, Pedro Roberto, A pesquisaação em estudos interdisciplinares: análise de critérios que só a prática pode revelar.

Interface - Comunicação, Saúde, Educação [online]. 2014, v. 18, n. 5, pp. 633-646.

Disponível em: <https://doi.org/10.1590/1807-57622014.0026>. Acesso em: 13 Ago 2020 . 
Epub 26 Set 2014. ISSN 1807-5762. https://doi.org/10.1590/1807-57622014.0026.

VARGAS, Ariel; ROCHA, Heloísa Vieira da; FREIRE, Fernanda Maria Pereira. Promídia: produção de vídeos digitais no contexto educacional. Novas Tecnologias na Educação. V. 5 No 2, Dezembro, 2007. Disponível em: http://www.cinted.ufrgs.br/ciclo10/artigos/1bAriel.pdf VASCONCELOS, C. M.; PASCHE, D. F. O sistema único de saúde. In: G. W. S. Campos et al (Orgs). Tratado de saúde coletiva. São Paulo/Rio de Janeiro: Hucitec/Fiocruz, 2009. p.531-562

Recebido em: (09/06/2020)

Aceito em: (18/10/2020) 